\title{
Is it Possible to Predict Earnings per Share?
}

\author{
Miroslav Kmet'ko ${ }^{1, *}$, Eduard Hyránek ${ }^{1}$ \\ ${ }^{1}$ University of Economics, Faculty of Business Management, Department of Business Finance, \\ Dolnozemska cesta 1, 85104 Bratislava, Slovakia
}

\begin{abstract}
The publication of quarterly results of publicly traded companies can have a significant impact on the valuation of their shares. This is mainly concerned with the valuation of the shares, whether it is correct, and at the same time as a prediction of the overall annual financial results. It In most of the analysed companies, we found that most of the year-on-year changes were negative. It is also not possible to draw a clear conclusion about the linear relationship between the percentage change pf surprises and the change in the market price of shares. It should also be noted that the share price in the monitored days may be affected by the current market situation. What this means in practice is that, despite the positive results and the negative mood, stock prices can end up in negative values. However, this situation was not the subject of our research. Therefore, we used a correlation coefficient for this dependence, which represent the mutual movement.
\end{abstract}

\section{Introduction}

The publication of quarterly results of publicly traded companies can have a significant impact on the valuation of their shares. During this period, which is called the Earning Season and is always started by company Alcoa (as the first component of the S\&P 500 index) are closely watched by investors. This is mainly concerned with the valuation of the shares, whether it is correct, and at the same time as a prediction of the overall annual financial results. Outside this period, company share's prices are mainly influenced by market sentiment and by published news about company, such as statements from top managers, change of managers, mergers and acquisitions, new products etc.

Major bank, investment firms and brokers, employ number of analysts, who publish their investment recommendations for the main areas of the expected financial situation of the analysed company. To this we may include: quarterly earnings per share (EPS), annual earnings per share, annual sales, and these estimates are prepared several periods to the future. There are also analytics opinions for the current price, whether the share price is undervalued or overvalued, in the form of recommendations to buy, hold or sell the shares.

\footnotetext{
* Corresponding author: miroslav.kmetko@euba.sk
} 


\section{The aim of the paper and methodology}

The aim of this paper is how the analysts were accurate in estimating quarterly earnings per share. For every major U.S. exchange-traded company, there are several analysts from different companies. The median value (which is standard measure for expectations for financial markets) is subsequently published for the estimates. Not as is usually used arithmetic mean.

According to the information source, therefore, it also depends on sources to analysts and their views and therefore estimates of quarterly EPS can vary. For our analysis, we used data from the page www.finance.yahoo.com. We recalculate the percentage changes of surprises based on the data, to two decimal places because the real data on the page works with multiple decimal places.

In addition to comparing real data with expected data (EPS), we also used a comparison of real changes of quarterly changes of EPS by tracking the current quarter against the same quarter of the same quarter of the previous year. We also analysed the changes in the share prices in the form of the final price before the results were published to the final price of the share on the day the information was published.

Lastly, the correlation coefficient between the surprise of the current EPS value and the price change was calculated.

For the analysis, given by the current situation, we selected the largest producers of dgug makers (according to the market capitalisation) in the USA Specifically sorted from the biggest: Johnson \& Johnson (JNJ), Pfizer Inc. (PFE) a Merck \& Co., Inc. (MRK).

\section{Estimation of EPS}

The fundamental analysis of joint stock companies is devoted a lot of literature. However, it is necessary to distinguish whether we focus on ex-post or ex-ante analysis e.g. Weaver [1] or Damodaran [2]. But is it sufficient? According to Yohn [3] he highlights that financial statement analysis research has slowly evolved and has received limited attention from academics.

The analysis of expected EPS and real EPS can be based on a comparison of short selling. If the investors expect worse results than analysts expect, they will start selling shares briefly. As the authors state Hou et al. [4]: "We examine the relationship between short selling and analyst optimism bias of earnings forecasts of stocks in China. Lastly, we document that short selling information improves the accuracy of earnings forecasts. Similarly Li et al. [5]: "Further analysis of the role of short-sales constraints in the sensitivity of stock prices to bad earnings news implies that short sales can enhance informational efficiency".

Boehmer et al. [6]: "Importantly, short sellers use both public news and private information to anticipate news regarding earnings and analysts. Information that may have a significant impact on investor sentiment". As indicated by Yang and Wu [7]: "combined effect of investor sentiment and public information on the asset price, the mechanism of public information shock on investor sentiment, and how the shock impacts the asset pricing.

From the behavior point of view Murkherjee and De [8]: "the proxy for rational behavior is investor's use of private predisclosure information during earnings announcement periods, while the disposition effect they display serves as an estimate of their behavioral bias."

Also pandemic situation affect earnings. Landier and Thesmar [9]: "Forecasts over 2020 earnings have been progressively reduced by $16 \%$."

The reaction to the currently published profit figures also depends on the concrete capital market. According to Gaston a Jarne [10] there is an evidence that the magnitude of the reward (penalty) for companies meeting (failing to meet) earnings forecasts differs on the 
market. Chi et. Al. [11]: "The stock price inflation is partly explained by greater earnings surprises and more positive investor reaction to the surprises."

The sensitivity of stock prices to published results is also influenced by the frequency of their publication Arif a De George [12] : "We find that the returns of semi-annual earnings announcers (i.e., low reporting frequency stocks) are almost twice as sensitive. " The time aspect of the publication was also analysed by Adams and Neururer [13]: "we find evidence that uncertainty and volatility risk premiums are higher for firms that report later in the quarter. "

It is also linked to analysts'recommendations when it is forecasting profits. Research in this area has been tested by Billing et al. [14]: "Our evidence suggests that this negative relation results from analysts revising recommendations upward for higher expected earnings growth but failing to also adjust downward for a related decrease in expected returns arising from a decrease in investor risk aversion. " Clarkson et al. [15]: "Finally, our results show that target prices are useful in predicting future stock returns beyond earnings forecasts and commonly used risk proxies. "

\section{Research results and discussion}

We will analyse individual companies based on selected criteria. We will start with the company with the highest capitalisation and continue with companies to lower capitalisation. But it's important to remember that that we don't take into account other factors impacting the shares prices.

\subsection{Company JNJ}

We're starting with JNJ. First, we will analyse the relationship of changes in the current quarters compared to estimates to the current changes in EPS. This is represented in Figure 1.

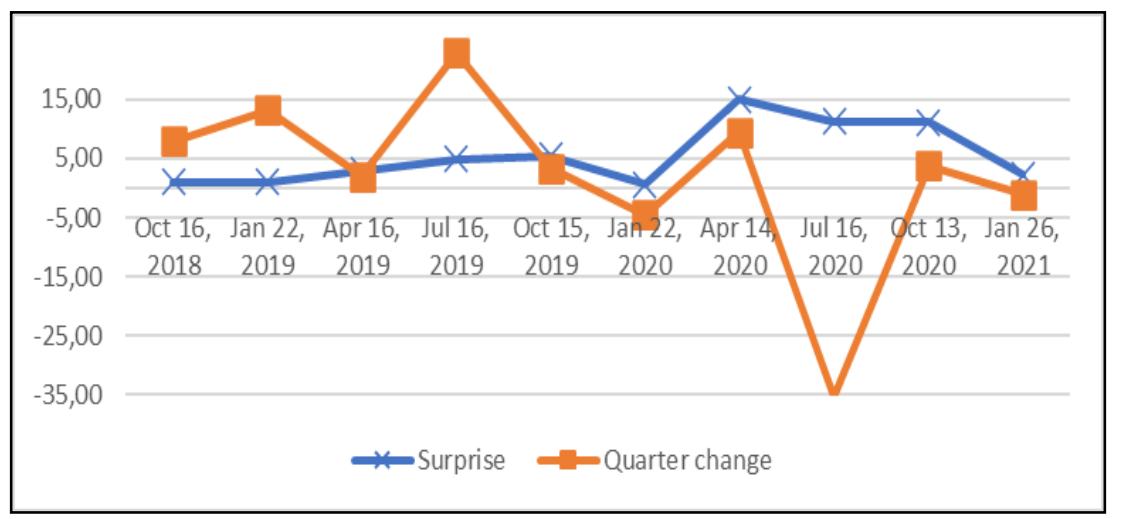

Fig 1. Earning surprise and quarterly change, own processing

Despite the high volatility of the quarterly results, the surpsises against the expected values were not so significant. Which means that analysts predicted these changes, they expected these changes to be less than they actually were.

In the next figure we present what was the real reaction of investors, in share prices, to the real published EPS data. 


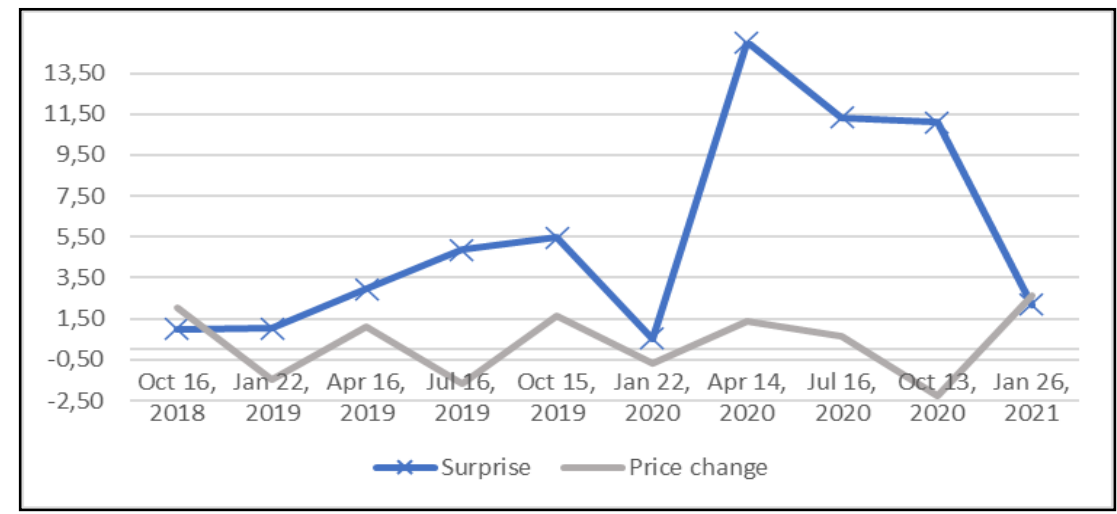

Fig. 2. Earning surprise and change in share prices, own processing

According to the figure, it is not possible to directly predict how the stock price will change with regard to the surprises in the financial resultss. Even in October 2020, despite positive information, stock prices fell.

\subsection{Company PFE}

PFE company is the second company in terms of market capitalization, producing drugs in the US.

As in the previous company, we will start here with an analysis of the changes in quarter changes in EPS as well as with the actually published financial results. The results are presented in figure 3 .

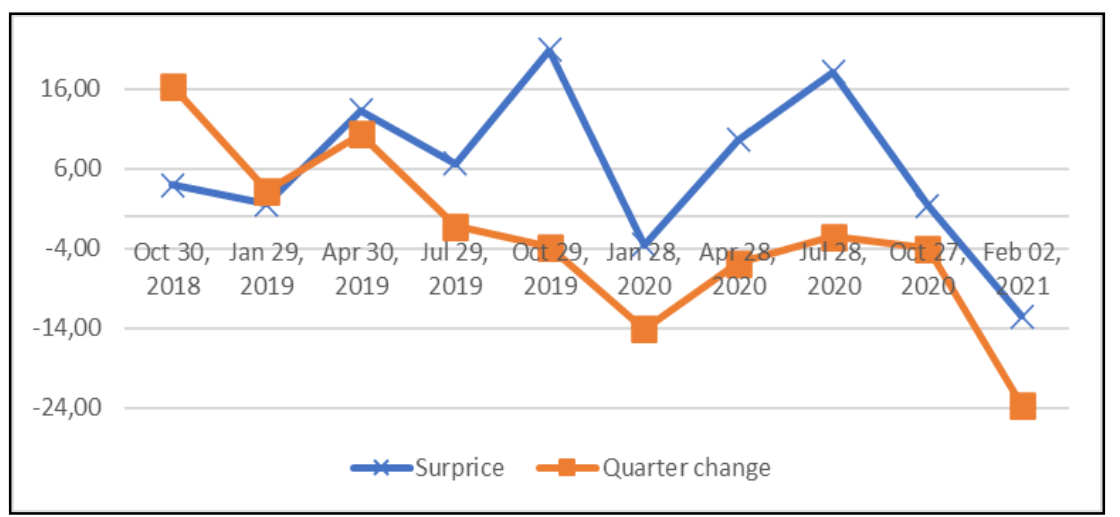

Fig. 3. Earning surprise and quarterly change, own processing

The gradual decline in quarterly results is surprising, The year-on-year declining change was expected by analysts, but it was significantly underestimated to the current values published by the company. It is looks like findings of Balashov and DeVides [16] we find that analysts can predict breaks in earnings strings by issuing less favorable earnings estimates ahead of a break announcement.

How the stock price reacted in view of the surpices of the published EPS is shown in figure 4 [17]. 


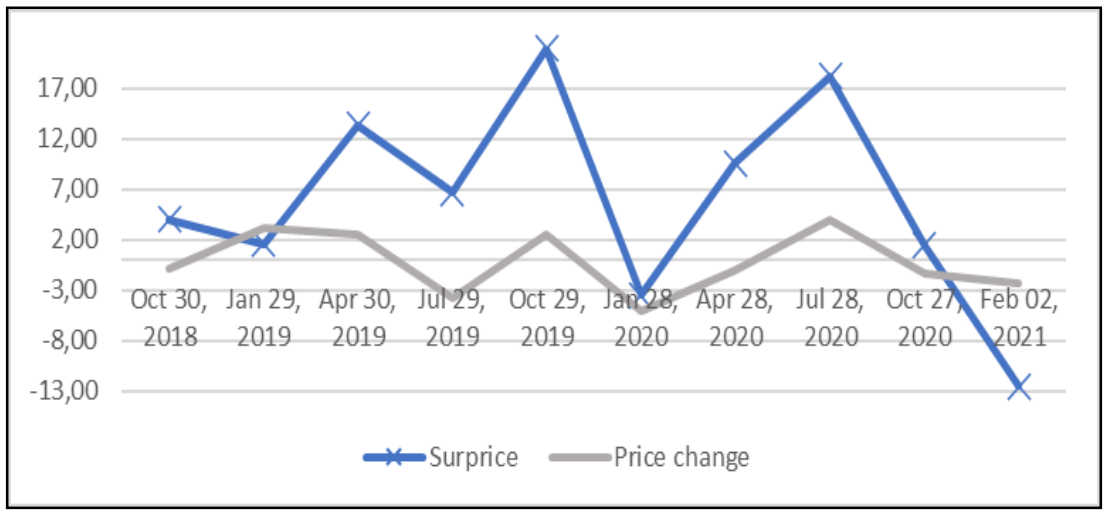

Fig. 4. Earning surprise and change in share prices, own processing.

In this case, the share price reacted in accordance with the value of the EPS surprice. For this company, if the investor can correctly predict the value of EPS, he can significantly gain from this surprise.

\subsection{Company MRK}

Compared to PFE, the year-to-year change in EPS is rather positive. In most quarters, teh change was grater than $10 \%$. The development is shown in figure 5 .

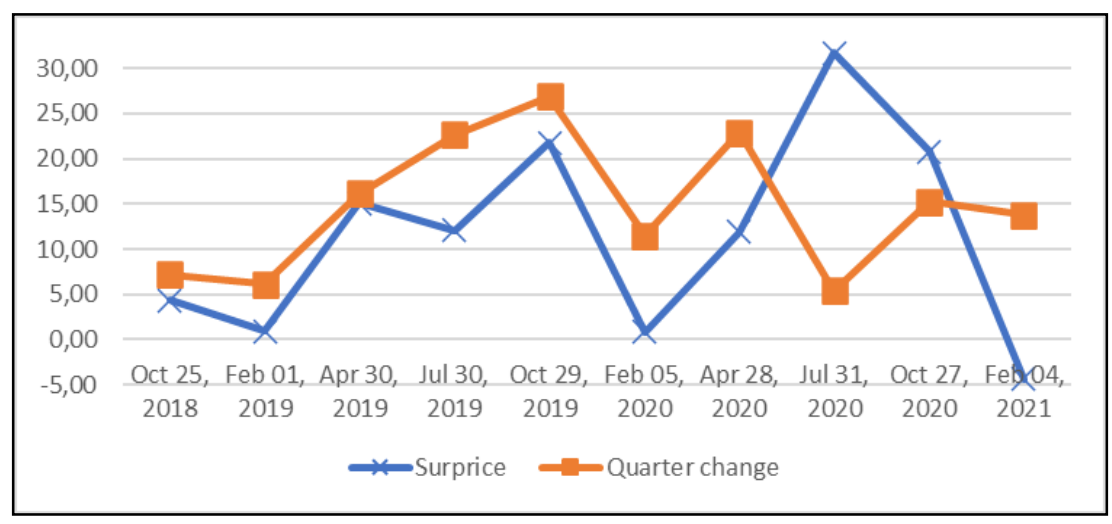

Fig. 5. Earning surprise and quarterly change, own processing

Based on the above development, it can be stated that the real were for all almost better than expected, except for the last monitored quarter.

How the share price reacted to thes published results is shown in the following figure 6 . 


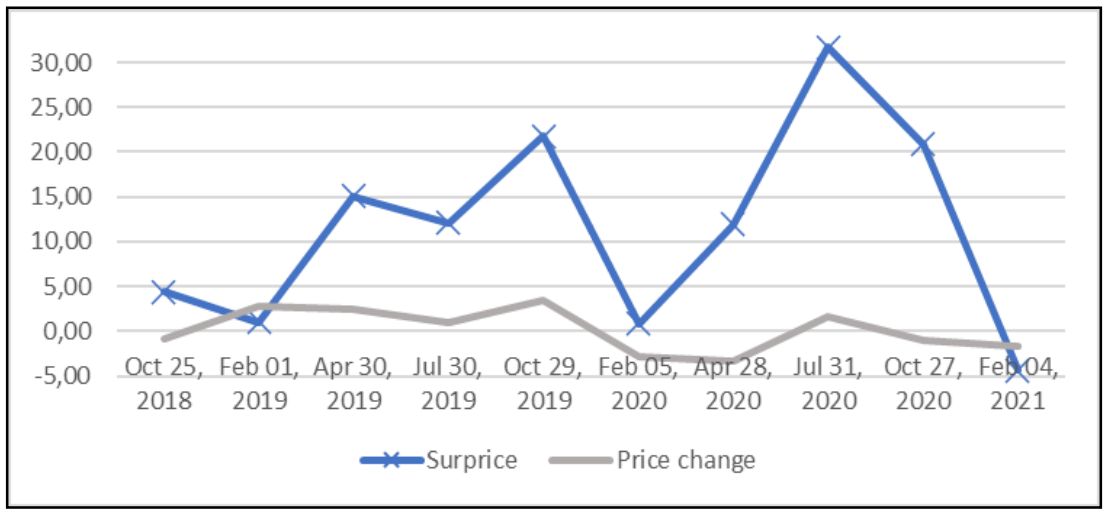

Fig. 6. Earning surprise and change in share prices, own processing.

According to the figure, it is so clear that the share price did not react to the published value of EPS as the analysts would predict. At the highest value of the surprise, the highest percentage change in price was not recorded. However, it can be stated that despite some positive changes in values in EPS, the share price decreased.

\section{Conclusion}

In most of the analysed companies, we found that most of the year-on-year changes were negative. It is also not possible to draw a clear conclusion about the linear relationship between the percentage change pf surprises and the change in the market price of shares. Therefore, we used a correlation coefficient for this dependence, which represent the mutual movement.

If we focus on the JNJ company, the correlation coefficient is at the level of $-0,07$. This value explains that it is not possible to draw any conclusions about the surprise of EPS and the change in price.

Conversely, for PFE, the value of the correlation coefficient is 0,64 . Thus, there is a strong dependence between the better EPS values that have been published to analyst's forecasts. It is therefore highly likely that if the company reports better estimates, the share price will increase. But it is necessary to stated that the EPS of this company on a long-term basis is declining in the long-term run.

The last company MRK has a correlation coefficient of 0,41 . This value is in the middle among analysed companies. It is likely that stock price will rise if the value of the surprise is positive, but to the given value of the correlation coefficient, it is not possible to confirm this with high probability.

It should also be noted that the share price in the monitored days may be affected by the current market situation. What this means in practice is that, despite the positive results and the negative mood, stock prices can end up in negative values. However, this situation was not the subject of our research.

The article was elaborated within the VEGA project no. 1/0462/19 Implementing key determinants into performance models as tools financial management under the current conditions. (100\%)

\section{References}

1. S.C. Weaver, The essentials of financial analysis. McGraw-Hill Education. 480 pp. ISBN 0-07-176836-X (2012) 
2. A. Damodaran, Investment valuation : Tools and techniques for determining the value of any asset. $3^{\text {rd }}$ edition. Wiley. 992 pp. ISBN 1-118-01152-X (2012)

3. T.L. Yohn, Research on the use of financial statement information for forecasting profitability. Accounting and Finance 60, 3 (2020)

4. D.S. Hou, Q.B. Meng, K.C. Chan, Does short selling reduce analysts' optimism bias in earnings forecasts? Research in International Business and Finance 56, April (2021)

5. Z. Li, M.T. Tian, G.D. Ouyang, F.H. Wen, Relationship between investor sentiment and earnings news in high- and low-sentiment periods. International Journal of Finance and Economics 26, 2 (2021)

6. E. Boehmer, C.M. Jones, J. Wu, X. Zhang, What do short sellers know. Review of Finance 24, 6 (2020)

7. C. Yang, H. Wu, Investor sentiment with information shock in the stock market. Emerging Markets Finance and Trade 57, 2 (2021)

8. S. Murkerjee, S. De, When are investors rational? Journal of Behavioral Finance 20, 1 (2019)

9. A. Landier, D. Thesmar, Earnings expectations during the COVID-19 crisis. Review of Asset Pricing Studies 10, 4 (2020)

10. B.K. Billings, S. Keskek, S. Pierce, The predictability of future earnings growth and the relation between aggregate analyst recommendation changes and future returns. Accounting Review 96, 1 (2021)

11. S.C. Gaston, J.I.J. Jarne, An international comparison of incentives for earnings management in order to meet analysts forecasts. Spanish Accounting Review 24, 1 (2021)

12. J.D. Chi, M. Gupta, S.A. Johnson, Short-horizon incentives and stock price inflation. Journal of Corporate Finance 65, December (2020)

13. S. Arif, E.T. De George, The dark side of low financial reporting frequency: Investors'reliance on alternative sources of earnings news and excessive information spillovers. Accounting Review 95, 6 (2020)

14. P. Clarkson, A. Nekrasov, A. Simon, I. Tutticci, Target price forecasts: The role of the 52-week high price and recent investor sentiment. Journal of Business Finance and Accounting 47, 9-10 (2020)

15. T. Adams, T. Neururer, Earnings announcement timing, uncertainty, and volatility risk premiums. Journal of Futures Markets 40, 10 (2020)

16. V.S. Balashov, Z.B. DeVides, Can analysts predict breaks in earnings strings? Review of Accounting and Finance 18, 4 (2019)

17. YAHOO. Finance, www.finance.yahoo.com (2021) 